\title{
Relationships between IGF-I concentration and age at first calving of Holstein-Friesian heifers with their survival up to third calving
}

J S Brickell, D C Wathes

Royal Veterinary College, Hertfordshire, United Kingdom

Email: jbrickell@rvc.ac.uk

Introduction Dairy cows survive on average only three lactations; this severely limits opportunities for on-farm selection of breeding cows in addition to presenting a welfare issue and causing economic loss. Furthermore, around $15 \%$ of liveborn heifers fail to reach first calving, and about $20 \%$ of those which do are culled or die during their first lactation. The somatotrophic axis (growth hormone, insulin-like growth factor-I [IGF-I], insulin and glucose) in the female dairy calf is of key importance for growth, development, and reproductive function. We have previously found a strong positive correlation between IGF-I concentration and growth in heifers between 1 and 6 months of age, and both were also associated with age at first calving (AFC). The aim of this study was to determine if IGF-I concentration, or AFC, are useful in predicting future survival up to third calving of Holstein-Friesian animals on dairy farms.

Materials and methods A total of 17 dairy farms across southern England milking Holstein-Friesian cows were recruited during 2003 and 2004. Recruited heifers $(\mathrm{n}=337)$ were monitored from birth until they calved for a third time. For animals failing to reach third calving, the number of calvings they achieved before they died, or were culled or sold was recorded. Blood samples were collected at one $(28 \pm 0.8 \mathrm{~d}, \mathrm{n}=334)$, six $(184 \pm 0.8 \mathrm{~d}, \mathrm{n}=317)$ and fifteen $(452 \pm 3 \mathrm{~d}, \mathrm{n}=305)$ months of age, and at weeks $-1,+1$ and +8 around first and second calving for the measurement of plasma IGF-I using commercial ELISA kits. Age at first service (AFS) $(15 \pm 0.1$ months, $\mathrm{n}=305)$ and AFC ( $26 \pm 0.2$ months, range 21 to 37 months, $\mathrm{n}=286)$ were recorded. Animals were subdivided on the basis of the number of calvings they achieved; $0(\mathrm{n}=51), 1(\mathrm{n}=68)$, $2(\mathrm{n}=55)$, or $3(\mathrm{n}=163)$. One-way analysis of variance (ANOVA) was initially used to compare IGF-I concentration, AFS and AFC according to the number of calvings. To further investigate relationships which showed a significant relationship with the number of calvings, analyses were performed using a linear mixed effects model with posthoc LSD tests, including farm as a random effect.

Results Of the initial 337 heifers recruited, $85 \%(n=286$ ) reached first calving, whilst only $48 \%$ ( $n=163$ ) survived to third calving. Infertility was the main reason for culling after first $(n=20 / 68)$ and second $(n=20 / 55)$ calving. Plasma IGF-I concentration increased during the rearing period up to 15 months, then declined at each subsequent calving before increasing again by 8 weeks PP; concentrations were lower around second than first calving. IGF-I concentrations according to the number of calvings achieved are presented in Table 1. Heifers only calving once had lower IGF-I levels at 15 months compared to those calving three times $(P<0.05)$. Animals calving only twice had lower concentrations immediately before and after second calving compared to animals reaching their third lactation $(P<0.05)$. Animals calving three times were younger at first service $(15 \pm 0.1$ months) and at first calving ( $25 \pm 0.2$ months $)$ compared to heifers only calving once ( $16 \pm 0.4$ months, and $27 \pm 0.4$ months, respectively) (Figure 1).

Table 1 Plasma IGF-I concentration $(\mathrm{ng} / \mathrm{ml})$ during the rearing period, and around first and second calving, according to number of calvings achieved.

\begin{tabular}{llllll}
\hline & \multicolumn{3}{l}{ Number of calvings } & \multirow{P}{*}{$\begin{array}{l}P \text {-value\# } \\
\mathrm{a}<\mathrm{b}\end{array}$} \\
\cline { 2 - 5 } & $0, \mathrm{n}=51$ & $1, \mathrm{n}=68$ & $2, \mathrm{n}=55$ & $3, \mathrm{n}=163$ & NS \\
\hline 1 month & $40 \pm 5$ & $40 \pm 3$ & $43 \pm 4$ & $46 \pm 2$ & NS \\
6 months & $92 \pm 9$ & $83 \pm 5$ & $87 \pm 5$ & $90 \pm 3$ & 0.03 \\
15 months & $99 \pm 9$ & $97 \pm 4^{\mathrm{a}}$ & $99 \pm 5$ & $109 \pm 2^{\mathrm{b}}$ & 0.03 \\
\hline Pre-calving1 & & $73 \pm 4$ & $66 \pm 4$ & $71 \pm 2$ & $\mathrm{NS}$ \\
Week 1 PP & & $34 \pm 3$ & $40 \pm 5$ & $42 \pm 2$ & 0.1 \\
Week 8 PP & & $56 \pm 3$ & $58 \pm 3$ & $59 \pm 2$ & NS \\
\hline Pre-calving 2 & & & $49 \pm 4^{\mathrm{a}}$ & $61 \pm 3^{\mathrm{b}}$ & 0.04 \\
Week 1 PP & & & $17 \pm 2^{\mathrm{a}}$ & $27 \pm 2^{\mathrm{b}}$ & 0.03 \\
Week 8 PP & & & $41 \pm 4$ & $44 \pm 2$ & NS
\end{tabular}

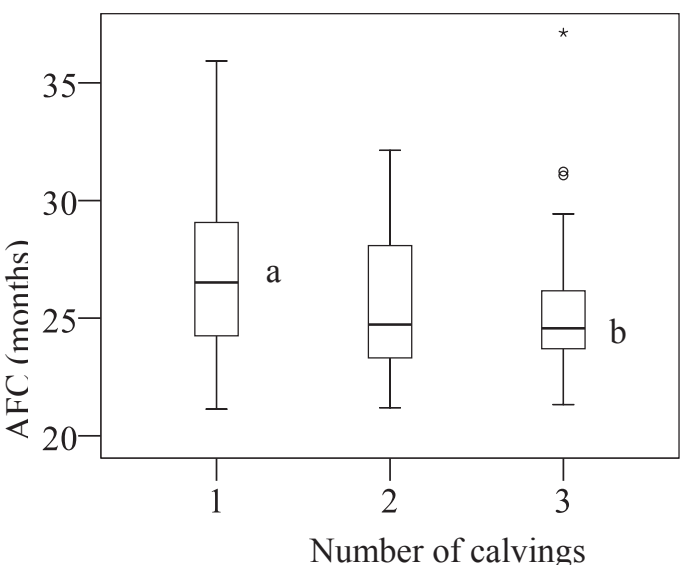

\#Linear mixed model with farm included as a random effect.

$\mathrm{PP}=$ postpartum

Figure $1 \mathrm{AFC}$ according to number of calvings; 1 $(27 \pm 0.4$ months, $\mathrm{n}=68), 2(26 \pm 0.4$ months, $\mathrm{n}=55)$, and 3 ( $25 \pm 0.2$ months, $\mathrm{n}=163)$. $\mathrm{a}>\mathrm{b}, P<0.001$

Conclusion Only half the heifers recruited at birth survived until a third calving. Animals failing to complete a single lactation are clearly uneconomic to rear as replacement heifers. Heifers culled after first calving, mainly for infertility, had lower IGF-I concentrations at 15 months, and animals culled after second calving had lower concentrations immediately before and after calving. This suggests that differences in the somatotrophic axis may affect their fertility and hence longevity, and these differences may be amplified on entering second lactation. Animals reaching their third lactation were younger at first breeding and calving, highlighting the importance of early growth and development in terms of their subsequent performance. 